Maurer School of Law: Indiana University

Digital Repository @ Maurer Law

2006

\title{
The New International Health Regulations: An Historic Development for International Law and Public Health
}

\author{
David P. Fidler \\ Indiana University Maurer School of Law, dfidler@indiana.edu \\ Lawrence O. Gostin \\ Georgetown University Law Center
}

Follow this and additional works at: https://www.repository.law.indiana.edu/facpub

Part of the Health Law and Policy Commons, and the International Law Commons

\section{Recommended Citation \\ Fidler, David P. and Gostin, Lawrence O., "The New International Health Regulations: An Historic Development for International Law and Public Health" (2006). Articles by Maurer Faculty. 370. \\ https://www.repository.law.indiana.edu/facpub/370}

This Article is brought to you for free and open access by the Faculty Scholarship at Digital Repository @ Maurer Law. It has been accepted for inclusion in Articles by Maurer Faculty by an authorized administrator of Digital Repository @ Maurer Law. For more information, please contact rvaughan@indiana.edu. 


\title{
The New International Health Regulations: An Historic Development for International Law and Public Health
}

\author{
David P. Fidler and Lawerence O. Gostin
}

$\mathrm{T}$ he World Health Assembly (WHA) adopted the new International Health Regulations (IHR) on May 23, 2005. The new IHR represent the culmination of a decade-long revision process and an historic development for international law and public health. The new IHR appear at a moment when public health, security, and democracy have become intertwined, addressed at the highest levels of government. The United Nations (UN) Secretary-General Kofi Annan, for example, identified IHR revision as a priority for moving humanity toward "larger freedom." ${ }^{2}$ This article analyzes the new IHR and their implications for global health and security in the 21st century.

\section{The IHR and the Revision Process}

The WHA instructed the WHO Director-General (DG) to revise the IHR in 1995 because the Regulations did not provide an effective framework for addressing the international spread of disease. ${ }^{3}$ Doubts about the IHR's effectiveness had, however, been present long before 1995. The critiques identified the narrow scope of the regulations (applying only to a small number of infectious diseases), the lack of compliance by states, and the absence of a strategy for responding to rapid changes in public health's global economic and technological environments.

The resurgence of infectious diseases in the $1980 \mathrm{~s}$ and 1990s highlighted the IHR's ineffectiveness. Particularly troublesome were the IHR's inapplicability to the spread of endemic diseases, such as tuberculo- sis and malaria, and new diseases, such as HIV/AIDS and viral hemorrhagic fevers. Concern also existed that some governments lacked the capacity or political will to report and respond to diseases of international importance. By 1995, WHO understood that the revised IHR would have to break with traditional approaches and construct a novel framework for health and security in an era of accelerating globalization. The innovative framework began to emerge with WHO's first proposal in January 1998, which had a broad scope and permitted the use of non-governmental data sources. ${ }^{5}$

The outbreak of Severe Acute Respiratory Syndrome (SARS) in 2003 accelerated the IHR revision process. WHO viewed its response to SARS as a "roll-out" of ideas being crafted in the IHR revision process. ${ }^{6}$ In the wake of WHA resolutions on SARS and the IHR revision process in May 2003,7 WHO issued a complete proposed text in January 2004, which served as the basis for WHO's regional consultations through the spring and summer of $2004 .^{8}$ These consultations led to a revised proposed text, issued in September 2004 for the first intergovernmental negotiations held in November 2004.9 Following the first negotiating session, the Chair of the negotiations promulgated a "Chair's text" for consideration at the second negotiating session in February 2005..$^{10}$ The negotiations were completed in May 2005 prior to the WHA's annual meeting, ${ }^{11}$ at which the Assembly adopted the new IHR.

David P. Fidler, J.D., is Professor of Law and Harry T. Ice Faculty Fellow, Indiana University School of Law - Bloomington and Senior Scholar, Center for Law and the Public's Health, Georgetown and Johns Hopkins Universities. Lawrence O. Gostin, J.D., L.L.D., (Hon.), is Associate Dean and Professor, Georgetown University Law Center; Professor, Johns Hopkins University; and Director, World Health Organization Collaborating Center on Public Health Law and Human Rights. Dean Gostin is Adjunct Professor and Fellow at Oxford University and a lifetime Member of the Institute of Medicine. 


\section{The New IHR: An Important Development in Global Health Governance}

The new IHR contain 66 articles organized into ten parts and include nine annexes (see Table). The purpose of the new IHR is "to prevent, protect against, control and provide a public health response to the international spread of disease in ways that are commensurate with and restricted to public health risks, and which avoid unnecessary interference with international traffic and trade" (Article 2). The IHR seek to balance the state's right to protect its people's health with obligations to take health-protecting actions in ways that do not unnecessarily interfere with international trade and travel.

The new IHR capture this balancing task by providing that "States have...the sovereign right to legislate and to implement legislation in pursuance of their health policies. In doing so they should uphold the purpose of these Regulations" (Article 3.4). By calibrating health and trade interests, the IHR resonate with international trade law under the World Trade Organization (WTO), which also recognizes the state's right to restrict trade for health purposes but limits this right to ensure that restrictions are necessary. ${ }^{12}$ The synergies between the new IHR and international trade law emphasize that public health is embedded in an international system that facilitates economic activity through globalized markets. Finding effective ways of balancing public health and international economic activity has become critically important to the success of international trade and international health governance.

The new IHR radically depart from the traditional approach informing the old IHR. The new IHR transform the international legal context in which states will exercise their public health sovereignty in the future. As examined below, the new IHR expand the scope of the IHR's application, incorporate international human rights principles, contain more demanding obligations for states parties to conduct surveillance and response, and establish important new powers for WHO.

The transformative nature of the new IHR connects to growing consensus on the importance of public health to global governance in the 21st century. Over the decade during which the IHR revision unfolded, it became apparent that public health had emerged as critical to virtually every major global governance issue, ranging from national and international security, trade, and economic development, to environmental protection and human rights. The new IHR not only transform the traditional approach to international disease spread but they also represent a politically important opportunity for public health to engage expansively with the international community.

\section{Scope of the New IHR: An All-Risks Approach}

As indicated above, the old IHR applied only to a short list of infectious diseases whose spread was historically associated with trade and travel (e.g., cholera, plague, and yellow fever). The Regulations now encompass public health risks whatever their origin or source (Article 1.1), including: (1) naturally occurring infectious diseases, whether of known or unknown etiological origin; (2) the potential international spread of non-communicable diseases caused by chemical or radiological agents in products moving in international commerce; and (3) suspected intentional or ac- 
cidental releases of biological, chemical, or radiological substances.

This "all risks" approach embodies an important conceptual shift concerning public health's role in the IHR. Trade calculations determined the old IHR's scope, but risks to human health define the new IHR's scope. The result is a set of rules with more public health legitimacy, flexibility, and adaptability. This expanded public health approach is found throughout the new IHR. Reporting health events, handling epidemiological data, making WHO recommendations, and limiting national health measures apply across the spectrum of health events. The expanded scope creates a more demanding framework than anything that ever appeared in the traditional approach.

\section{Incorporation of Human Rights Principles: Autonomy, Privacy, and Liberty}

The traditional approach to international disease spread developed prior to the emergence of international human rights law. The new IHR incorporate human rights principles, recognizing the effects of public health interventions on civil and political rights, such as security of person and freedom of movement. ${ }^{13}$

\section{The New IHR and General Human Rights Principles} The new IHR proclaim that " $[\mathrm{t}]$ he implementation of these Regulations shall be with full respect for the dignity, human rights and fundamental freedoms of persons" (Article 3.1). This provision raises the question whether the new IHR conform to existing international human rights principles. For a public health measure to restrict a civil and political right lawfully, the measure must (1) respond to a pressing public or social need; (2) pursue a legitimate aim; (3) be proportionate to the legitimate aim; and (4) be no more restrictive than is required to achieve the purpose sought by restricting the right. ${ }^{14}$ The rights-restricting measure must also be implemented in a non-discriminatory manner (International Covenant on Civil and Political Rights (ICCPR), Articles 2.1 and 26). Individuals deprived of liberty must be treated with humanity and respect for the inherent dignity of the human person (ICCPR, Article 10.1).

The new IHR generally reflect the requirements in international human rights law. The Regulations require states parties to identify a public health risk that justifies imposing health measures against persons (Articles 23.2, 31.1, 31.2, and 43.1), apply an appropriate health response to such risk (Articles 23.2, $23.5,30,31.2$, and 43.2), and implement measures that are no more intrusive or invasive of persons than reasonably available alternatives that would achieve the level of health protection desired (Articles 23.2,
31.2, and 43.1). These disciplines also apply to WHO recommendations made under the new IHR (Article 17). All health measures must be applied in a transparent and non-discriminatory way (Article 42). In addition, states parties must treat travelers with respect for their dignity, human rights and fundamental freedoms and minimize any discomfort or distress associated with health measures, including by treating them with courtesy and respect; taking into consideration their gender, socio-cultural, ethnic, or religious concerns; and providing adequate food, water, accommodation, baggage protection, medical treatment, and means of communication for quarantined or isolated travelers (Article 32).

The extent to which the new IHR incorporate human rights principles means that international human rights law is relevant to the interpretation and implementation of the new IHR..$^{15}$ The Regulation's incorporation of human rights will suffer, however, if states parties do not integrate human rights thinking into the operation of their respective public health systems. As human rights problems with HIV/AIDS and other public health concerns suggest, making the new IHR's human rights elements effective will require commitment and vigilance. WHO and states parties should have human rights principles in mind as they build the public health capacities required by the new IHR.

\section{Informed Consent and Privacy}

The new IHR also contain provisions on the important human rights areas of informed consent and privacy. States parties cannot apply health measures to travelers without their prior express informed consent, except in situations that warrant compulsory measures (Articles 23.3 and 31.2). The new IHR also reflect the right to privacy by requiring states parties to preserve the confidentiality of personally identifiable information they receive from other states parties or WHO (Article 45.1). States parties and WHO must ensure that disclosure and processing of personal information in order to address a public health risk protects individual privacy (Article 45.2). The Regulations also require WHO to respond to individuals who want to review personally identifiable data WHO possesses about them (Article 45.3).

Although an improvement over the traditional approach in terms of recognizing the importance of informed consent and privacy, problems and questions remain. For example, the new IHR fall short in terms of protecting human rights with regard to compulsory measures applied in the absence of informed consent. The rules relevant to compulsory measures only oblige states parties to apply the least intrusive and invasive measure with respect to medical examinations but not 


\section{The new IHR require WHO to share information it receives from non-governmental sources with all states parties and relevant intergovernmental organizations when necessary to enable responses to public health risks.}

to vaccinations, other prophylaxis, isolation, or quarantine (Articles 23.2 and 31.2). In addition, the Regulations do not include due process protections necessary when states apply compulsory measures.

In terms of privacy, the new IHR mandate confidential treatment of personal health data by states parties "as required by national law" (Article 45.1). Similarly, the requirement of states parties to protect privacy in addressing public health risks must be fulfilled "in accordance with national law" (Article 45.2). These provisions may make privacy protections under the new IHR relative to disparate levels of national privacy protection rather than subject to internationally recognized privacy standards.

\section{National Public Health Capacities: Surveillance and Response}

The new IHR require states parties to develop, strengthen, and maintain core surveillance and response capacities (Articles 5.1 and 13.1 and Annex 1). The old IHR had requirements for public health capabilities only at points of entry and exit. The farreaching provisions in the new IHR shore up major weaknesses in global strategies created by inadequate national surveillance and response capabilities.

The new IHR reflect, however, states' concerns about sovereignty. States parties do not have to fulfill the capacity obligations until 2012 - five years after the new IHR enter into force in 2007 (Articles 5.1 and 13.1). A state party can obtain a two-year extension by submitting a justified need and an implementation plan to WHO (Articles 5.2 and 13.2); and, in exceptional circumstances, it can request a further two-year extension that the DG has the power to grant or deny (Articles 5.2 and 13.2).

Although the new IHR's provisions on surveillance and response capacities recognize the critical need for capacity building, questions remain about the handling of this issue. The most pressing question concerns the availability of financial and technical resources needed to improve national core capacities, especially in developing and least developed countries. WHO's duties to provide surveillance and response assistance (Articles $5.3,13.3$, and 13.6) do not address its own shortage of funds and personnel. The new IHR also contain no obligations on states parties to provide financial and technical resources to support capacity-building. Although the new IHR urge states parties to provide financial and technical resources, these provisions are either non-binding (Article 13.5) or weak (Article 44.1). Given the financial demands created by other global health problems, such as increasing access to HIV/AIDS treatment ${ }^{16}$ and meeting the health-related Millennium Development Goals, ${ }^{17}$ the new IHR's silence on how the economic demands of the core capacity objectives will be met is a serious problem for which the new IHR provide no apparent answers or strategies.

\section{Notification Obligations: Reporting Health Events to WHO}

The new IHR require states parties to notify WHO of all events within their territories that may constitute a public health emergency of international concern (Article 6), defined as "an extraordinary event which is determined...(i) to constitute a public health risk to other States through the international spread of disease and (ii) to potentially require a coordinated international response" (Article 1.1). A "decision instrument" is used to guide states parties in determining whether a disease event may constitute a public health emergency of international concern (Annex 2) (See Figure).

In keeping with the new IHR's expanded scope, the notification obligations reflect a radically different, and more demanding, approach to addressing the international spread of disease. The notification provisions place a premium on states parties having sufficient surveillance capacities to detect disease incidents, assess them under the decision instrument, and report disease events that may constitute public health emergencies of international concern. As discussed above, whether many WHO member states have, or can develop, surveillance capacities sufficient to support these notification obligations remains a serious question.

Another problem looms for the new IHR's notification requirements. States parties often violated the old IHR by failing to report cases of diseases subject to the Regulations because they feared other countries would implement economically damaging trade or travel restrictions. ${ }^{18}$ Will the more expansive and demanding notification requirements in the new IHR avoid the wide-spread non-compliance that undermined the old IHR? Answering this question requires considering the new IHR's approach to information supply and verification, which constitutes its strategy for countering non-compliance with notification obligations. 
Decision Instrument for the Assessment and Notiffication of Events that May Constitute a Public Mealth Emergency of International Concern (New URR, Annex 2)

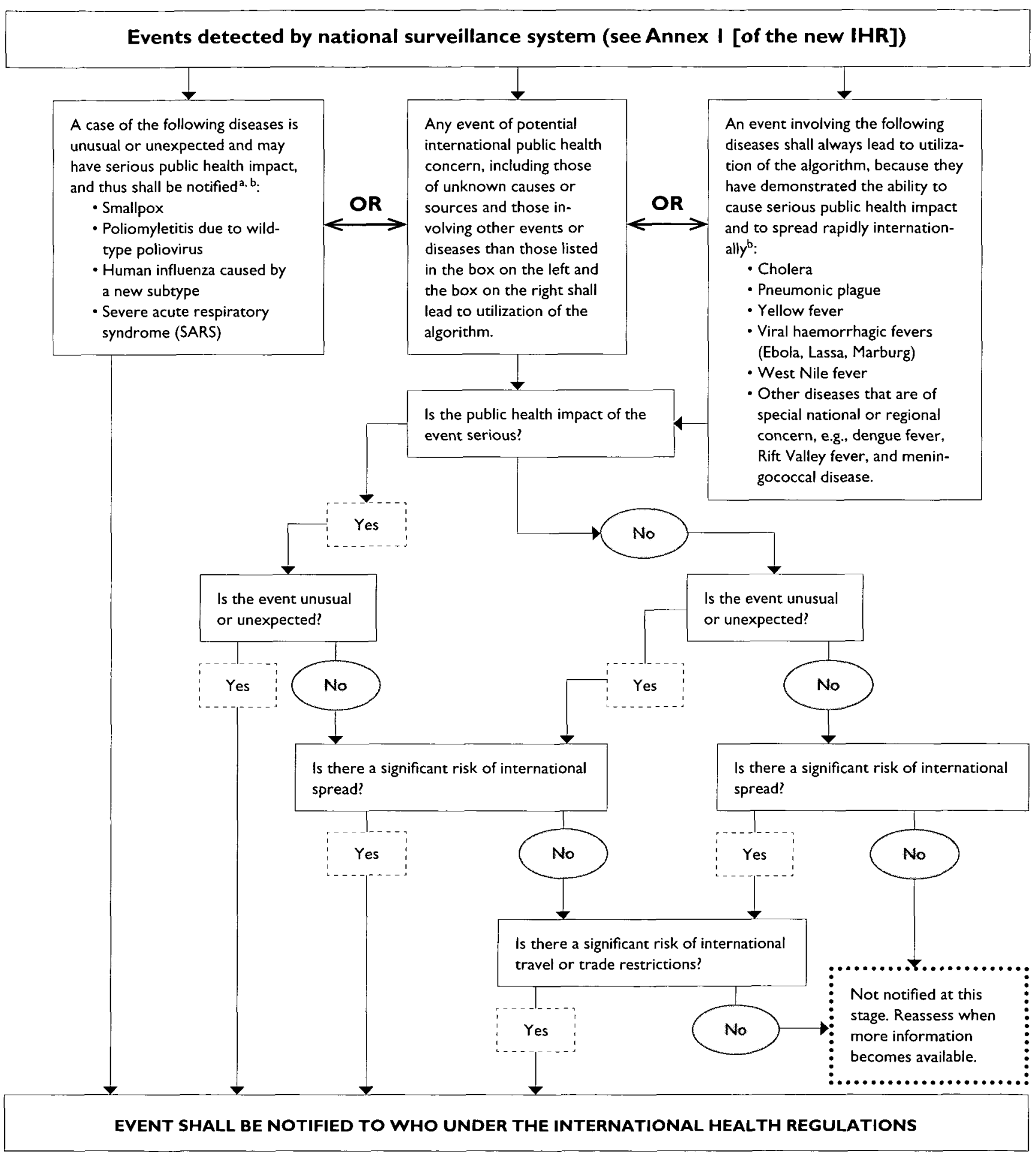

as per WHO case definitions.

b The disease list shall be used only for purposes of these Regulations. 


\section{Data and Verification Provisions: Unofficial Sources of Information}

The old IHR limited WHO to officially using information provided by states parties. This limitation handicapped WHO's ability to respond to disease events if a government refused to notify WHO of incidents, supply needed information, or otherwise cooperate. By contrast, the new IHR allow WHO to "take into account reports from sources other than notifications or consultations" from or with governments and to seek verification of such information from states parties in whose territories the events are allegedly occurring (Articles 9.1 and 10.1). States parties must respond to $\mathrm{WHO}$ verification requests (Article 10.2). The new IHR require WHO to share information it receives from non-governmental sources with all states parties and relevant intergovernmental organizations when necessary to enable responses to public health risks (Article 11.1).

From the beginning of the IHR revision process, WHO identified access to non-governmental sources of information as critical to constructing an effective global surveillance system..$^{19}$ Harnessing new information technologies, such as the Internet, for global surveillance has been at the heart of WHO's Global Outbreak Alert and Response Network (GOARN). GOARN - a collaborative network of institutions and experts that pools human and technical resources for rapid identification, confirmation, and response to outbreaks of international importance - is centrally important to the new IHR's functioning. ${ }^{20}$

WHO demonstrated the power of having access to non-governmental sources of information during the SARS outbreak. ${ }^{21}$ Globalization has significantly decreased the state's ability to control the flow of epidemiological information into and out of its territory, and thus its prospects of keeping serious disease events hidden from international scrutiny. The avian influenza outbreaks in Asia also teach this lesson.

WHO's access to non-governmental information, its authority to request verification from states parties, and its power to share such information with the international community increase incentives for states parties to comply with the notification requirements. Further, the new IHR's information and verification provisions mitigate the consequences of non-compliance with notification obligations because $\mathrm{WHO}$ will, in all likelihood, learn of disease events through other sources, triggering the information verification and dissemination processes. The best chance states parties have to minimize adverse economic consequences from disease events is to be transparent and cooperate with WHO and other countries in addressing the threats. In short, the information and verification pro- visions privilege global health governance over state sovereignty.

The new IHR contain, however, a provision that bears watching to see how it affects the flow of nongovernmental information. The Regulations require WHO to share non-governmental information with states parties "and only where it is duly justified may WHO maintain the confidentiality of the source" (Article 9.1). The general requirement on WHO to disclose the source of non-governmental information might deter non-state actors from supplying WHO with information, particularly individuals living under authoritarian regimes. In contrast to its protections for confidentiality of health-related personal information, the Regulations generally require WHO to supply information on persons who are non-official sources of information. The new IHR provide no guidance for determining under what circumstances WHO would be justified in maintaining the confidentiality of non-state sources. Such determinations might involve WHO having to assess the likelihood that governments may punish individuals in their jurisdictions for disseminating disease-related information. Thus, decisions to protect confidentiality of non-state sources will likely involve political controversy for WHO.

\section{Declaration and Recommendation Powers}

The new IHR grant two other important powers to WHO that never appeared in the old IHR. First, the new IHR accord WHO the authority to determine whether a disease event constitutes a public emergency of international concern (Article 12). States parties have to notify disease events that may constitute such emergencies, but the DG determines if disease events are public health emergencies of international concern. Although the DG must consult with states parties in whose territories disease events are occurring, he or she is not bound to follow their views. In other words, a state party's refusal to cooperate does not bar WHO action.

Second, if the DG determines that a public health emergency of international concern is occurring, then he or she shall issue non-binding, temporary recommendations to states parties on the most appropriate ways to respond (Article 15). The DG may also issue non-binding, standing recommendations on routine, periodic application of health measures for specific, ongoing public health risks (Article 16). The new IHR contain criteria for issuing temporary or standing recommendations (Article 17) and examples of the kinds of measures WHO could recommend (Article 18). These powers allow WHO to provide leadership on what health measures are appropriate from scientific and public health perspectives and on the proper ways 
to balance health protection with respect for human rights and acknowledgement of trade concerns.

\section{Permissible Health Measures: Limits on National Public Health Interventions}

States parties to the new IHR are not legally bound to follow WHO temporary or standing recommendations; but the new IHR contain binding limits on the types of health measures states parties can take against public health risks. These limits are designed to ensure adequate health protection with minimal interference with international traffic and respect for human rights. Generally, states parties cannot require an invasive medical examination, vaccination or other prophylaxis as a condition of entry for any traveler (Article 31.1); nor can a state party require any health document for travelers other than those permitted by the new IHR or recommended by WHO (Article 35). The new IHR also regulate measures states parties can apply to ships, aircraft, goods, and containers (Articles 25-29, 33-34, and 41) and harmonize the types of health documents required from ships and aircraft (Articles 37-39).

The new IHR permit states parties to apply health measures that achieve the same or greater level of health protection than WHO recommendations or that are otherwise prohibited by the IHR (Article 43.1). Such health measures must be based on scientific principles, available scientific evidence, relevant guidance or advice from WHO, and cannot be more restrictive of international traffic or more invasive or intrusive to persons than reasonably available alternatives that would achieve the level of health protection sought (Articles 43.1-43.2).

These provisions resemble the approach taken to health-protecting measures in WTO agreements, such as the Agreement on the Application of Sanitary and Phytosanitary Measures (SPS Agreement). Unlike the SPS Agreement, however, the new IHR do not have a strong enforcement mechanism if states parties fail to comply with the obligations on permissible health measures. Enforcement of the SPS Agreement benefits from the mandatory WTO dispute settlement process. Dispute settlement in the new IHR is essentially voluntary (Article 56). Failure by states to comply with the old IHR undermined their effectiveness. The lack of an enforcement mechanism in the new IHR may mean that non-compliance with rules on permissible health measures becomes a problem.

\section{Rejections and Reservations}

As a treaty, the new IHR cannot legally bind states unless they consent to be bound. Therefore, states can reject the new IHR (Article 61) or formulate reservations to provisions to which they refuse to be bound (Article
62). The changes made by, and the more demanding nature of, the new IHR may create incentives for states to reject the revised Regulations or formulate reservations. A reservation becomes effective (1) if less than one-third of relevant states object to the reservation (Article 62.5); or (2) if at least one-third of relevant states object to the reservation, and the reserving state does not withdraw the reservation, when the WHO by majority vote approves the reservation as compatible with the IHR's object and purpose (Article 62.9). Rejections and reservations have to be made within 18 months of the date of the new IHR's adoption (Article 59.1). The United States has already indicated that it will submit a "narrowly tailored" reservation providing that it will implement the IHR in a manner consistent with American federalism. ${ }^{22}$ The process of making and reviewing reservations bears monitoring because of the potential for reservations to weaken the new IHR's universal application.

\section{Political Controversies in the IHR Reform Process}

Three political conflicts emerged during the negotiations to revise the IHR that threatened to stall or even prevent final adoption: conflicts of law with other international regimes; the role of WHO in combating biological, chemical, and nuclear terrorism; and the relationship of Taiwan to the new IHR regime.

\section{Conflicts of International Law}

WHO member states expressed concerns that the expanded scope of the new IHR would bring the Regulations into conflict with other international agencies and treaties that addressed cross-border health risks - e.g., the International Atomic Energy Agency (nuclear accidents); ${ }^{23}$ the World Trade Organization (health measures that restrict international trade); ${ }^{24}$ and the Codex Alimentarius Commission (food standards and guidelines to protect consumer health and promote trade in safe products). WHO addressed these concerns by demonstrating that few conflicts existed; amending the negotiating text to remove the small number of possible conflicts; ${ }^{25}$ and adding provisions to facilitate cooperation and coordination between WHO and other international organizations (e.g., Articles 14, 17(f), 57.1).

\section{Biological, Chemical, and Nuclear Terrorism}

How the revised IHR would apply to suspected intentional releases of biological, chemical, and radiological agents proved highly controversial. Negotiating drafts required states parties to share information with WHO if they had evidence of a suspected intentional release of a biological, chemical, or radiological agent. 
This proposal reflected the belief that appropriate public health responses were needed whether the risk was naturally occurring, accidental, or intentionally caused. However, the proposal was politically charged as it touched on issues of national and international security related to weapons of mass destruction. Concern was expressed that WHO's public health mission could be to, public health risks (Article 2). Provision of information under Article 7 is no different than the provision of information for any disease event or public health risk to which the new IHR apply, meaning that WHO would be focused on the health risk only. "Health measure" is defined to exclude law enforcement or security measures (Article 1.1). Although information WHO gath-

\section{Less clear is whether the new IHR might embroil WHO in the politics of national and international security to the detriment of its core public health functions. Although it makes some experts uncomfortable, the potential for terrorism involving weapons of mass destruction connects public health to security concerns.}

compromised if it had to investigate whether states had violated arms control treaties or UN Security Council resolutions. ${ }^{26}$

The new IHR handle these concerns awkwardly, reflecting difficult negotiations. The new IHR do not contain any specific requirement on information-sharing concerning suspected intentional releases. What remains is a weaker provision: "If a State Party has evidence of an unexpected or unusual public health event within its territory, irrespective of origin or source, which may constitute a public health emergency of international concern, it shall provide WHO with all relevant public health information" (Article 7). However, this article, combined with the expanded scope, makes clear that the new IHR apply to a suspected intentional release of a biological, chemical, and radiological agent. The understanding issued by the United States that the new IHR apply to all "health threats - chemical, biological, and radiological - and all causes and modes of events - regardless whether they are naturally occurring, accidental, or deliberate" is correct. ${ }^{27}$

Less clear is whether the new IHR might embroil WHO in the politics of national and international security to the detriment of its core public health functions. Although it makes some experts uncomfortable, the potential for terrorism involving weapons of mass destruction connects public health to security concerns. The anthrax attacks in the United States in 2001 demonstrated that public health responses to bioterrorism are critical aspects of national and homeland security. The new IHR recognize this unfortunate reality.

At the same time, the new IHR limit WHO's role to public health activities in these security-sensitive contexts. The new IHR's purpose states that the Regulations involve prevention, protection, control, and response activities concerning the international spread of disease in ways commensurate with, and restricted ers and analyzes would be important in assessments of whether a state violated obligations under arms control agreements or Security Council resolutions, the new IHR do not put WHO in the position of making such assessments.

Despite these attempts to contain WHO's role in situations involving possible violations of arms control and other security obligations, the new IHR do not settle the controversies about WHO's relationship to security concerns related to weapons of mass destruction. Following recommendations made by a high-level panel of experts ${ }^{28}$ and the UN Secretary-General, ${ }^{29}$ the Security Council could decide to intervene in a situation involving naturally occurring diseases or a suspected intentional release of biological, chemical, or radiological agents in a way that involves WHO in politically difficult circumstances. Whether such an intervention by the Security Council would be warranted is not an issue that the new IHR could address.

\section{The Tairwan Problem}

The standoff between China and Taiwan entered the politics of the IHR revision process. Following the SARS outbreak in 2003, during which Taiwan required assistance from WHO, Taiwan advocated for being included in the new IHR regime. Taiwan argued that the new IHR should have universal geographical coverage to be effective in the era of globalized disease threats. During the negotiations, China refused to allow Taiwan to participate formally in the new IHR.

What remains of this controversy is found in the principle that " $[t]$ he implementation of these Regulations shall be guided by the goal of their universal application for the protection of all people of the world from the international spread of disease" (Article 3.3). Taiwan interprets this provision as "a basis for Taiwan to make contact with the WHO directly without China's inter- 
ference." ${ }^{30}$ China disagrees and points to a memorandum it negotiated with WHO in May 2005 that requires China's consent before WHO has any direct contact with Taiwan. ${ }^{31}$ In short, the new IHR do not resolve the Taiwan-China problem, nor could the IHR revision process be expected to produce rapprochement between Taiwan and China.

\section{The New IHR and the Future of Global Health Governance}

The new IHR contain an international legal regime unprecedented in the history of the relationship between international law and public health. The revised Regulations promise to become a centerpiece for global health governance in the 21st century. As the UN Secretary-General's support for the IHR revision illustrates, ${ }^{32}$ the new IHR have global governance significance far beyond anything contemplated under, or achieved by, the old IHR. Whether the issue involves international security, trade, economic development, environmental degradation, UN reform, or human rights, policy makers and experts have identified public health as a central governance challenge nationally and internationally in the 21st century. The transformational nature of the new IHR create a regime that has the potential to contribute significantly to the general global governance mission of improving national and international health. The Regulations provide a framework that supports not only improved international cooperation on health but also the strengthening of national health systems, producing more robust health governance horizontally among states and vertically within them.

The new IHR's novelty should not, however, obscure hard realities facing its future. WHO was systematically using non-governmental surveillance information from GOARN's establishment in 1998, well before the IHR revision process was completed; and this strategy would have continued whether or not the new IHR had been adopted. More difficult issues arise with producing effective responses to identified public health risks. For decades, WHO has issued recommendations on many public health problems; but the mixed record of state compliance with WHO guidance should temper enthusiasm for the new IHR's recommendation provisions. The political controversies that surrounded WHO's more aggressive actions during SARS may deter WHO from taking similar actions under the new IHR. Laments about the erosion of global and local public health capabilities suggest that WHO's decadeslong effort to improve health conditions in developing countries has also met with only qualified success. The new IHR will not change this dynamic overnight, particularly when the Regulations generate no fresh financial resources to support capacity-building. Com- pliance with international legal restrictions against the implementation of health measures that unnecessarily restrict trade or infringe on human rights has not, in the past, been stellar, as illustrated by how non-compliance helped destroy the old IHR's effectiveness. Whether the quantity and quality of compliance with the new IHR's rules on health measures are better will not depend on any improved enforcement mechanism because the Regulations do not create one.

The new IHR are no "magic bullet" for global health problems. Previous transformations in international law's relationship with public health have, over time, atrophied into insignificance. The history of the old IHR tells just such a story. Further, the new IHR's relevance to some pressing global health problems, such as increasing access to HIV/AIDS treatment in the developing world or stemming the "brain drain" of health workers from developing to developed countries, ${ }^{33}$ is not apparent. Controversies and problems surrounding the threat of avian influenza also suggest that the new IHR do not cut through the tangled knot of very hard political, economic, scientific, and public health choices governments must make to address this public health emergency of international concern.

The new IHR are the product of a decade of work by WHO and its member states, and the revised Regulations have been designed to be a robust governance framework far into the future. Harvesting the new IHR's benefits for global health requires understanding not only the difficulties this task faces but also the potential the Regulations represent. At present, this potential exists mainly on paper, which is why the implementation phase is critical. WHO needs to approach implementation with the energy and vision it demonstrated during SARS. The seminal achievement of the new IHR constitutes only the end of the beginning. The hard work of making this transformative revision of global health governance effective for individuals, states, and the international community now begins.

\section{References}

1. World Health Assembly, Revision of the International Health Regulations, WHA58.3 (May 23, 2005).

2. UN Secretary-General, In Larger Freedom: Towards Development, Security, and Human Rights for All: Report of the Secretary-General, A/59/2005 (March 21, 2005).

3. World Health Assembly, Revision and Updating of the International Health Regulations, WHA48.7 (May 12, 1995).

4. P. Dorelle, "Old Plagues in the Jet Age: International Aspects of Present and Future Control of Communicable Diseases," Chronicle of the World Health Organization 23 (1969): 103-111; E. Roelsgaard, "Health Regulations and International Travel," Chronicle of the World Health Organization 28 (1974): 265-268; B. Velimirovic, “Do We Still Need International Health Regulations?" Journal of Infectious Diseases 133 (1976): 478-482.

5. World Health Organization, Provisional Draft of the International Health Regulations (Geneva, Switzerland: World Health Organization, January 1998). 
6. World Health Organization, Severe Acute Respiratory Syndrome (SARS): Status of the Outbreak and Lessons for the Immediate Future (Geneva, Switzerland: World Health Organization, 2003).

7. World Health Assembly, Severe Acute Respiratory Syndrome (SARS), WHA56.29 (May 28, 2003); World Health Assembly, Revision of the International Health Regulations, WHA56.28 (May 28, 2003).

8. World Health Organization, International Health Regulations: Working Paper for Regional Consultations, IGWG/IHR/Working paper/12.2003 (January 12, 2004); L. O. Gostin, "International Infectious Disease Law: Revision of the World Health Organization's International Health Regulations," JAMA 291 (2004): 2623-2627.

9. World Health Organization, Review and Approval of Proposed Amendments to the International Health Regulations: Draft Revision, A/IHR/IGWG/3 (September 30, 2004).

10. World Health Organization, Review and Approval of Proposed Amendments to the International Health Regulations: Proposal by the Chair, A/IHR/IGWG/2/2 (January 24, 2005).

11. World Health Organization, Revision of the International Health Regulations: Note by the Secretariat, A58/4 (May 16, 2005).

12. World Health Organization and World Trade Organization, WTO Agreements छे Public Health: A Joint Study by the WHO and the WTO Secretariat (Geneva, Switzerland: World Health Organization, 2002).

13. International Covenant on Civil and Political Rights, United Nations Treaty Series 171 (December 19, 1966): 999.

14. UN Economic and Social Council, UN Sub-Commission on Prevention of Discrimination and Protection of Minorities, Siracusa Principles on the Limitation and Derogation of Provisions in the International Covenant on Civil and Political Rights, UN Doc. E/CN.4/1985/4, Annex, 1985.

15. Vienna Convention on the Law of Treaties, United Nations Treaty Series 331 (May 23, 1969): 1155.

16. World Health Organization, The 3 by 5 Initiative, available at <http://www.who.int/3by5/en/> (last visited December 12, 2005).

17. World Health Organization, Achievement of Health-Related Millennium Development Goals: Report by the Secretariat, A58/5 (May 13, 2005).

18. D. P. Fidler, International Law and Infectious Diseases (Oxford, England: Clarendon Press, 1999).

19. World Health Organization, The International Response to Epidemics and Applications of the International Health Regulations: Report of a WHO Informal Consultation, WHO/EMC/IHR/96.1 (December 11-14, 1995).

20. World Health Organization, Global Defense Against the Infectious Disease Threat (Geneva, Switzerland: World Health Organization, 2002).
21. D. P. Fidler, SARS, Governance, and the Globalization of Disease (Basingstoke, England: Palgrave Macmillan, 2004).

22. Statement for the Record by the Government of the United States of America Concerning the World Health Organization's Revised International Health Regulations, May 23, 2005. Press Release, U.S. Mission to the United Nations in Geneva, at $<\mathrm{http}: / / \mathrm{www}$. us-mission.ch/Press2005/0523IHRs.htm> (last visited January 9, 2006).

23. Convention on Assistance in the Case of a Nuclear Accident or Radiological Emergency, September 26, 1986, 1457 United Nations Treaty Series 133; Convention on Nuclear Safety, July 5, 1994, 1963 United Nations Treaty Series 317.

24. General Agreement on Tariffs and Trade, April 15, 1994, in World Trade Organization, The Legal Texts: The Results of the Uruguay Round of Multilateral Trade Negotiations (Cambridge, England: Cambridge University Press, 1999): 424-492; Agreement on the Application of Sanitary and Phytosanitary Measures, April 15, 1994, in World Trade Organization, The Legal Texts: The Results of the Uruguay Round of Multilateral Trade Negotiations (Cambridge, England: Cambridge University Press, 1999): 59-72.

25. World Health Organization, Review and Approval of Proposed Amendments to the International Health Regulations: Relations with Other International Instruments. A/IHR/IGWG/INF. DOC./1 (September 30, 2004).

26. G. S. Pearson, The UN Secretary-General's High Level Panel: Biological Weapons Related Issues (Strengthening the Biological Weapons Convention, Review Conference Paper No. 14) (May 2005).

27. Supra note 22.

28. UN Secretary-General's High-Level Panel on Threats, Challenges, and Change, A More Secure World: Our Shared Responsibility (New York, New York: United Nations, 2004).

29. Supra, note 2

30. J. Rickards, "Taiwan-WHO Ties Improving, Officials Say," China Post, May 26, 2005 available at <http://www.chinapost.com. tw/archive/detail.asp?cat $=1 \& i d=62934$ $>$ (last visited January 9,2006 ).

31. X. Yen, "Taiwan's WHO Bid Has No Legal Basis," China Daily, May 31, 2005, at 4.

32. See UN Secretary-General, Press Release, World Health Assembly's Revised Regulations "Bold and Necessary Step" to Protect Global Public Health, Says Secretary-General (May 23, 2005) SG/SM/9886, SAG/365.

33. World Health Assembly, International Migration of Health Personnel: A Challenge for Health Systems in Developing Countries, WHA58.17 (May 25, 2005). 